\title{
ENHANCED RECOVERY PATHWAYS (ERAS) IMPLEMENTATION IN MINIMALLY INVASIVE ESOPHAGECTOMY; AN EARLY EXPERIENCE
}

\author{
Aaishah Riaz, Bilal Umair, Asif Asghar, Muhammad Imtiaz Khan, Raheel Khan, Azfar Bilal \\ Combined Military Hospital/National University of Medical Sciences (NUMS) Rawalpindi Pakistan
}

\begin{abstract}
Objective: To evaluate the impact of enhanced recovery pathways (ERAS) on hospital stay and postoperative outcomes in patients undergoing minimally invasive esophagectomy in comparison to conventional pathway.

Study Design: Quasi experimental study.

Place and Duration of Study: Thoracic Surgery Department, Combined Military Hospital Rawalpindi Pakistan, from Jul 2018 to Mar 2020.

Methodology: A total of 80 patients who underwent minimally invasive esophagectomy were divided in two groups. Group A underwent ERAS pathway and group B underwent conventional pathway. Both groups were compared for demographic characteristics, mean ICU stay, length of hospital stay, commencement of oral intake, and time of chest drain removal, readmission rates, postoperative morbidity and mortality.

Results: There was no significant difference in age, gender and diagnostic indication among both groups. ERAS group was found to have shorter mean ICU stay $(1.18 \pm 0.55$ vs $2.06 \pm 1.10$ days $p<0.012)$, shorter hospital stay $(7.50 \pm 1.23$ vs $11.6 \pm 3.65$ days, $p<.001)$, earlier commencement of oral feeding (4.30 \pm 1.41 vs $9.10 \pm 4.26$ days, $p<0.001)$ and early removal of chest drains $(3.22 \pm$ vs $4.11 \pm 1.52 p<0.001)$; when compared to conventional group. Overall morbidity in ERAS group was 50 (40\%) versus $65 \%(81.25 \%)$ in conventional group. Mortality was same in both groups $(2.5 \%)$. There was no readmission in ERAS group.

Conclusion: ERAS in minimally invasive esophagectomy is safe and has positive impact on postoperative outcomes with marked reduction in overall morbidity in comparison to conventional regime. Results can be enhanced by ensuring better compliance to its key elements.
\end{abstract}

Keywords: ERAS, Minimally invasive esophagectomy, Perioperative care, Postoperative outcome.

How to Cite This Article: Riaz A, Umair B, Asghar A, Imtiaz M, Khan R, Bilal A. Enhanced Recovery Pathways (ERAS) Implementation in Minimally Invasive Esophagectomy; An Early Experience. Pak Armed Forces Med J 2021; 71(6): 2082-2086. Doi: https://doi.org/10.51253/pafmj.v6i6.5943

This is an Open Access article distributed under the terms of the Creative Commons Attribution License (https://creativecommons.org/licenses/by-nc/4.0/), which permits unrestricted use, distribution, and reproduction in any medium, provided the original work is properly cited.

\section{INTRODUCTION}

Enhanced recovery after surgery protocol (ERAS) was first implemented in colorectal surgery in 1990's. ${ }^{1}$ Inspired by Danish Professor of surgery Henrik Kehlet, ERAS protocol discouraged conventional perioperative carep rinciples including prolonged fasting, mobility restrictions, mechanical bowel preparation, prolonged use of drains, and delayed oral feeding postoperatively. $^{2}$

ERAS is based on the minimization of surgical impact on patients' internal milieu. Reduction in surgical stress response not only lays the foundation for a swift recovery but also decreases the risk of organ dysfunction and post-operative morbidity, ${ }^{3}$ and ultimately shortens the hospital stay. ${ }^{4}$

ERAS has evolved over the years into a multimodality approach comprising of surgeons, anesthesiologists, critical care physicians, physio-therapists,

Correspondence: Dr Aaishah Riaz, Registrar Thoracic Surgery, Combined Military Hospital Rawalpindi Pakistan

Received: 12 Jan 2021; revision received: 15 Feb 2021; accepted: 16 Feb 2021 nutritionists and nursing staff collaborating to integrate its components into clinical practice. Apart from colorectal surgery, ERAS hasshown encouraging results ingastric, pancreatic, bariatric surgery as well as in non-gastrointestinal specialties. ${ }^{5}$ ERAS was introduced relatively late in esophagectomy due to complexity of surgical technique and increased likelihood of postoperative complications. ${ }^{6}$ Increased susceptibility to complications and protracted course can be attributed tohigh prevalence of malnutrition in esophageal cancer patients because of the dysphagia caused by the tumor and cancer cachexia resulting in significant weight loss and nutritional deficiencies. ${ }^{7}$ A worldwide review from high-volume centers performing esophagectomy showed overall morbidity of $59 \%$ with 30 -day and 90 day mortality of $2.4 \%$ and $4.5 \%$ respectively. ${ }^{8}$

Recently, with adaptation of minimally invasive esophagectomy, careful organ handling concepts and improvement in gastric conduit and anastomosis techniques, ERAS has started to show promising outcomes. 9,10 However, evidence based data on feasibility of ERAS in esophageal resection surgery is still scarce. 
We planned to study the impact of ERAS implementation on hospital stay, postoperative outcomes, morbidity and mortality in patients undergoing minimally invasive esophagectomy in our population and compared it to conventional regime.

\section{METHODOLOGY}

This quasi-experimental study was conducted at the Thoracic Surgery Department of a Tertiary Care Hospital, from July 2018 to March 2020. Institutional ethical review board approval was taken vide no 101/ 08/20(41) and informed consent was taken.

Sample size of 80 patients was calculated using world health organization sample size calculator, by using confidence interval $95 \%$, margin of error $5 \%$ and our estimated population size who required esophagectomy was 100 over mentioned period. ${ }^{11}$

Inclusion Criteria: The patients who underwent minimally invasive esophagectomy and gastric pull up for carcinoma esophagus or benign pathologies i.e., corrosive stricture, motility disorders and esophageal perforation were included.

Exclusion Criteria: Patients with multiple corrosive strictures requiring colonic/jejunal pull up were excluded.

Patients were grouped into ERAS and Conventional groupsby non-probabilityconsecutive sampling technique. Guidelines for ERAS protocol was defined by team members after comprehensive literature search. ERAS pathway involved active participation of surgeons, anesthetists, nursing care staff, physiotherapists, nutritionist, patients and their families throughout the perioperative phase. Preoperative phase started from patient counselling about the plan of management and its key elements such as respiratory and nutritional build up before surgery were emphasized. At risk subjects with comorbidities were optimized. Patients were encouraged to startincentive spirometric exercises and enhance intake of high caloric, high pro-tein diet if oral/enteral feed was possible to overcome nutritional deficiencies.

Patients were admitted 24 hours before surgery, pre-op fasting time was minimized. Intraoperative care included judicious IV fluids, continuation of two lung ventilation, prevention of acidosis and hypothermia. Minimally invasive technique to limit tissue handling, avoidance of perianastomotic drains and adequate analgesia were adapted to reduce postoperative respiratory complications and ventilatory dependence.
Postoperative care involved active participation of patients and their family, nursing staff, critical care team along with surgeons. Patient's progress was measured on daily task completion basis and support was provided to ensure adequate mobility andrespiratory rehabilitation in post op period. Earlyresumption of enteral and oral feeding was emphasized in ERAS group. Timeline of both eras and conventional protocol is displayed in Table-I.

Data were analyzed using Statistical Package for the social sciences (SPSS) version 23 Frequencies and percentages were compared for qualitative variables like gender, diagnosis, postoperative morbidity and mortality and mean with standard deviation was applied on quantitative entities like age, mean ICU stay, length of hospital stay, time of chest drain removal, time to commence oral intake and 30- day readmission rates. Chi square test and $\mathrm{t}$ test was used. The $p$-value $\leq 0.05$ was considered statistically significant.

\section{RESULTS}

A total of 80 patients who underwent minimally invasive esophagectomy were included in the study. Both groups were compared on basis of demographic data. Mean age was $50.8 \pm 20.2$ years range from 12-90 years. Mean age for group A was $52.3 \pm 21.5$ years and $49.4 \pm 17.6$ years for group B. Gender distribution showed $48(60 \%)$ male and $32(40 \%)$ females. Group A (ERAS) included 25 males and 15 females while group B (Conventional) included 23 males and 17 females. Table-II shows that mean ICU stay in group A was 1.18 \pm 0.55 days and in group B was $2.06 \pm 1.10$ days $(p=$ $0.012)$, mean hospital stay in group A was $7.50 \pm 1.23$ days and in group B was $11.60 \pm 3.65$ days $(p<0.001)$, mean oral feed day in group A was $4.30 \pm 1.41$ days and in group B was $9.10 \pm 4.26$ days $(p<0.001)$, mean chest tube removal in group A was $3.22 \pm 1.03$ days and in group B $4.11 \pm 1.52$ days ( $p=0.001$ ). Indication of esophagectomy included in both cohorts were ca esophagus; group A 27 (67.5\%) group B 30 (75\%), corrosive stricture; group A 9 (22.5\%), group B $7(17.5 \%)$, motility disorder; group A $3(7.5 \%)$, group B $2(5 \%)$ and $1(2.5 \%)$ case of esophageal perforation in each group.

Indication of esophagectomy included in both study groups were Carcinoma (CA) esophagus; group A $27(67.5 \%)$ group B $30(75 \%)$, corrosive stricture; group A 9 (22.5\%), Group B 7 (17.5\%), motility disorder; group A $3(7.5 \%)$, group B $2(5 \%)$ and $1(2.5 \%)$ case of esophageal perforation in each group. There was significant difference of complication in both groups as 
per Clavien Dindo classification $p<0.001$ Shown in Table-III.
ERAS was first implemented in esophageal resectional surgery by Robert Cerfolio in 2004. It has

Table-I: Post-operative care timeline for ERAS and Conventional groups.

\begin{tabular}{|c|c|c|c|c|c|c|c|c|}
\hline Timeline & \multicolumn{3}{|c|}{ ERAS group } & \multicolumn{5}{|c|}{ Conventional Group } \\
\hline Day ‘0’ & \multicolumn{3}{|c|}{$\begin{array}{l}\text { Stay in ICU/HDU. Started incentive spirometry, } \\
\text { sitting in bed after 6-8 hrs. }\end{array}$} & \multicolumn{5}{|c|}{ Stays in ICU } \\
\hline Day ' 1 ' & \multicolumn{3}{|c|}{$\begin{array}{l}\text { Out of bed mobilization, weaned off supplemental } \\
\text { O2.and stepped down from intensive care, judicious } \\
\text { fluid electrolyte replacement \& thromboprophylaxis }\end{array}$} & \multicolumn{5}{|c|}{ Encouraged to sit in bed. Incentive spirometry. } \\
\hline Day '2’ & \multicolumn{3}{|c|}{$\begin{array}{l}\text { NG and foley's catheter removed, jejunal feed trial } \\
\text { given, increase mobility and cycle ergometry started }\end{array}$} & \multicolumn{5}{|c|}{ Encouraged to sit out of bed, and incentive spirometry } \\
\hline Day '3’ & \multicolumn{3}{|c|}{$\begin{array}{l}\text { Chest drains removed. High caloric and protein } \\
\text { supplementation of jejunal feed. }\end{array}$} & \multicolumn{5}{|c|}{$\begin{array}{l}\text { Mobility out of bed encouraged. } \\
\text { NG removed. Feeding jejunostomy trial started if bowel } \\
\text { sounds are audible }\end{array}$} \\
\hline Day' $4^{\prime}$ & \multicolumn{3}{|c|}{$\begin{array}{l}\text { Oral sips started. IV fluid tapered. Ensured full } \\
\text { mobility }\end{array}$} & \multicolumn{5}{|c|}{$\begin{array}{l}\text { Jejunal feed to increment if patient has satisfactory bowel } \\
\text { movement }\end{array}$} \\
\hline Day ' 5 ' & \multicolumn{3}{|c|}{ Full jejunal diet with oral fluid supplementation. } & \multicolumn{5}{|c|}{$\begin{array}{l}\text { Tapered iv fluids, jejunal feeds augmentation. Chest and } \\
\text { abdominal drains to be removed }\end{array}$} \\
\hline Day 6-7 & \multicolumn{3}{|c|}{$\begin{array}{l}\text { Discharged on puree diet with home care guidelines } \\
\text { and when to return }\end{array}$} & \multicolumn{5}{|c|}{$\begin{array}{c}\text { Emphasis on improving mobility. Full jejunal feeds. Correct } \\
\text { electrolyte imbalance. }\end{array}$} \\
\hline Day 8-10 & \multirow{2}{*}{\multicolumn{3}{|c|}{$\begin{array}{l}\text { Follow up visit, encouraged to initiate semi solid oral } \\
\text { diet. }\end{array}$}} & \multicolumn{5}{|c|}{ Started oral feed. } \\
\hline Day 12-14 & & & & & $\begin{array}{r}\text { ured oral fluids are to } \\
\text { en attending physici } \\
\text { mana }\end{array}$ & $\begin{array}{l}\text { atedw } \\
\text { Ind p } \\
\text { at hon }\end{array}$ & $\begin{array}{l}\text { o dis } \\
\text { forta }\end{array}$ & $\begin{array}{l}\text { rge } \\
\text { to }\end{array}$ \\
\hline \multirow{2}{*}{\multicolumn{4}{|c|}{$\begin{array}{l}\text { Table-II: Me } \\
\text { Variables }\end{array}$}} & & & & \multirow{2}{*}{\multicolumn{2}{|c|}{$p$-value }} \\
\hline & & & & \multicolumn{3}{|c|}{ Conventional (Group B) (Days) } & & \\
\hline \multicolumn{2}{|c|}{ Mean ICU stay (days) } & \multicolumn{2}{|c|}{$1.18 \pm 0.55$} & \multicolumn{3}{|c|}{$2.06 \pm 1.10$} & \multicolumn{2}{|c|}{0.012} \\
\hline \multicolumn{2}{|c|}{ Mean Hospital stay (days) } & \multicolumn{2}{|c|}{$7.50 \pm 1.23$} & \multicolumn{3}{|c|}{$11.60 \pm 3.65$} & \multicolumn{2}{|c|}{$<0.001$} \\
\hline \multicolumn{2}{|c|}{ Oral feed day (days) } & \multicolumn{2}{|c|}{$4.30 \pm 1.41$} & \multicolumn{3}{|c|}{$9.10 \pm 4.26$} & \multicolumn{2}{|c|}{$<0.001$} \\
\hline \multicolumn{2}{|c|}{ Chest tube removal (days) } & \multicolumn{2}{|c|}{$3.22 \pm 1.03$} & & $4.11 \pm 1.52$ & & $<0.0$ & \\
\hline Table-III: Con & mparison of com & tion rate in the st & Inn & $\bar{C}$ & -Dindo classificat & & & \\
\hline $\begin{array}{l}\text { Study } \\
\text { Groups }\end{array}$ & $\begin{array}{c}\text { No } \\
\text { Complication }\end{array}$ & $\begin{array}{l}\text { Complications } \\
\text { Managed } \\
\text { Conservatively } \\
\text { Grade I \& II } \\
\end{array}$ & $\begin{array}{l}\text { Intervent } \\
\text { Local Anes } \\
\text { Grade }\end{array}$ & $\begin{array}{l}n \text { in } \\
\text { nesia } \\
\text { a }\end{array}$ & $\begin{array}{l}\text { Intervention in } \\
\text { General } \\
\text { Anesthesia } \\
\text { Grade IIIb }\end{array}$ & $\begin{array}{r}\mathbf{N} \\
\text { Faili } \\
\end{array}$ & $\begin{array}{l}\text { an } \\
\text { liring } \\
t \\
V\end{array}$ & $\begin{array}{c}p- \\
\text { value }\end{array}$ \\
\hline $\begin{array}{l}\text { ERAS } \\
\text { Group A }\end{array}$ & $24(60 \%)$ & $12(30 \%)$ & $2(5 \%$ & & - & & & \\
\hline $\begin{array}{l}\text { Conventional } \\
\text { Group B }\end{array}$ & $14(35 \%)$ & $18(45 \%)$ & $5(12.5$ & & $1(2.5 \%)$ & & & $<0.001$ \\
\hline
\end{tabular}

\section{DISCUSSION}

Esophageal resection is a highly technical procedure in gastrointestinal surgery associated with poor outcomes and significantly high rates of postoperative morbidity and mortality. ${ }^{11}$

Surgeons throughout the world have experimented multiple ways to reduce this significant morbidity and mortality. In an attempt to improve postoperative outcomes and to expedite recovery without increasing risk of complications, a multimodality approach has been applied in field of esophageal surgery after its promising results in colorectal, ${ }^{12}$ gastric, ${ }^{13}$ pancreatic, ${ }^{14}$ and hepatic, ${ }^{15}$ surgery. been proven that ERAS in esophagectomy is safe and effective in early rehabilitation and significantly shortens postoperative hospital stay. ${ }^{16,17}$

ERAS in cases of esophagectomy has not been studied in our population and local data is non-existent. We adapted ERAS protocols in our experience of minimally invasive esophagectomies and compared them with conventional regime. We intended to find out difference in removal of chest drains, commencement of oral feeding, ICU stay, hospital stay, readmission rate and 30 days post-operative morbidity and mortality. Post-operative complications were classified according to Clavien-Dindoclassification and compared for both groups. 
Oral feeding in conventional group was started on 9th postoperative day as compared to 4th day in ERAS with a significant $p$-value of $<0.001$. Our findings were in consistence with international data where oral feeding was commenced earlier in ERAS group ( $p$ value $<0.001$ ) and was well tolerated by minimally invasive esophagectomy patients without significant increase in pulmonary complications and anastomotic leakage. ${ }^{18}$ In this study, ERAS group had 20\% minor respiratory complications while conventional group had $27.5 \%$ respiratory (Clavien DindoI/II) complications and $12.5 \%$ vs $17.5 \%$ anastomotic leak. Hence no significant increase in morbidity was noted by introduction of early oral feeding. We did not find any association of anastomotic leak with early oral intake or removal of nasogastric tube as described by Pan et al. ${ }^{18}$

Lewis et al,19 conducted a meta-analysis that concluded that early enteral nutrition could reduce the risk of pulmonary complications, anastomotic leakage and mortality.

ERAS provides a standardized approach for respiratory rehabilitation in perioperative period. We ensured strict compliance to deep breathing exercises, early mobilization and cycle ergometry. Chest tubes were removed significantly earlier in ERAS group ( $p$ value 0.001 ). Recurrence of pleural effusion needing reinsertion of tube thoracostomy was only 5\% in ERAS vs $10 \%$ cases in conventional group. Early removal of chest drains helped patients gain targeted mobility earlier in postoperative course.

We observed reduction in mean ICU stay 1.18 vs 2.06 days, $p$-value $<0.012$ by adapting perioperative ERAS guidelines of goal directed fluid therapy, avoidance of hypothermia and acidosis, two lung ventilation, adequate analgesia and minimally invasive surgical technique. Liu et al, observed a significant decline in ICU stay from 3.5-1.5 days. $(p<0.001)$ by early extubation in operative room. ${ }^{20}$

Significant reduction in hospital stay was noted in ERAS group (7.5 vs 11.1 days) $p$-value $<0.001$. This observation has been endorsed by Pan et al, ${ }^{18}$ and Gaten by et al. ${ }^{21}$ Length of hospital stay was influenced by compliance to key elements of ERAS protocol and incidence of postoperative complication rate. Early alimentation, mobilization and removal of drains translated into early discharge. Our results were different from other studies in terms of not a single incidence of readmission within 30 days in ERAS group, Underwood et al, ${ }^{22}$ reported $14 \%$ readmission rate in ERAS intervention group in minimally invasive esophagec- tomy patients. Reason behind this observation in our study can be active participation of patient and their families for respiratory and nutritional rehabilitation in the postoperative period resulted in improved confidence and patient satisfaction at the time of discharge. We also had a very high threshold for readmission, as most of the minor class I complications were continued to be managed on outpatient basis.

Overall complication rate reported in our study was $52.5 \%$ which was less than morbidity in esophageal cancer resection surgery described by Low et al. ${ }^{8}$ Adaptation of ERAS pathway led to marked reduction in overall morbidity from $65-40 \%$. Majority of complications in both groups required expectant management (class I/II) $30 \%$ vs $45 \%$ while major complications (class IIIa and above) were only 10\% in ERAS and 20\% in Conventional group. Underwood et al, described major morbidity of $10 \%$ in comparison to $18 \%$ in the year preceding to adaptation of ERAS pathway. ${ }^{22}$ No significant difference was found in overall mortality rate $(2.5 \%)$ in both groups $(p=1.00)$.

To summarize, ERAS has modified perioperative care practices by encouraging multidisciplinary partnership. In doing so, it has helped bridge the gap between the patients and their treating physicians and also proved to have significant improvement in overall postoperative outcomes, shortened hospital stay without increase in overall morbidity and mortality risks.

We acknowledge that our sample size was small and included benign pathologies along with esophageal cancer that may have influenced overall complication rate. This limitation can be addressed by studying outcomes of ERAS implementation on benign esophageal resections which are known to have higher incidence of Clavien-Dindo grade IV complications. (25\% vs $20 \%, p=0.003$ and prolonged hospital stay in contrast to esophageal cancer surgery as described by Masabni et al. ${ }^{23}$ Multicenter trials with larger sample size are required for further validation of the results described in this study.

\section{CONCLUSION}

ERAS in minimally invasive esophagectomy is safe and has positive impact on postoperative outcomes with marked reduction in overall morbidity in comparison to conventional perioperative care regime. Results can be enhanced by ensuring better compliance to its key elements.

\section{Conflict of Interest: None.}

\section{Authors' Contribution}

AR: Data collection, interpretation and analsis and actual drafting of article, BU: Critical revision and final approval, 


\section{Enhanced Recovery Pathways}

AA: Design and conception, MI: Data interpretation and analysis, RK: Drafting and critical review, AB: Data collection

\section{REFERENCES}

1. Pisarska M, Małczak P, Major P, Wysocki M, Budzyński A, Pędziwiatr M. Enhanced recovery after surgery protocol in oesophageal cancer surgery: systematic review and meta-analysis. PLoS One 2017; 12(3): e0174382.

2. Ljungqvist O. ERAS-enhanced recovery after surgery: moving evidence-based perioperative care to practice. J Parenter Enteral Nutr 2014; 38(5): 559-566.

3. Dorcaratto D, Grande L, Pera M. Enhanced recovery in gastrointestinal surgery: upper gastrointestinal surgery. Dig Surg 2013; 30(1): 70-78.

4. Martin TD, Lorenz T, Ferraro J, Chagin K, Lampman RM, Emery KL, et al. Newly implemented enhanced recovery pathway positively impacts hospital length of stay. Surg Endosc 2016; 30(9): 4019-4028.

5. Pędziwiatr M, Mavrikis J, Witowski J, Adamos A, Major $\mathrm{P}$, Nowakowski M, et al. Current status of enhanced recovery after surgery (ERAS) protocol in gastrointestinal surgery. Med Oncol 2018; 35(6): 95.

6. Liu F, Wang W. Enhanced recovery after surgery (ERAS) programs for esophagectomy protocol for a systematic review and meta-analysis. Medicine (Baltimore) 2018; 97(8): e0016.

7. Arends J, Bachmann P, Baracos V, Barthelemy N, Bertz H, Bozzetti $\mathrm{F}$, et al. ESPEN guidelines on nutrition in cancer patients. Clin Nutr. 2017; 36(1): 1-48.

8. Low DE, Kuppusamy MK, Alderson D, Cecconello I, Chang AC, Darling G, et al. Benchmarking complications associated with esophagectomy. Ann Surg 2019; 269(2): 291-298.

9. Ford SJ, Adams D, Dudnikov S, Peyser P, Rahamim J, Wheatley TJ,et al. The implementation and effectiveness of an enhanced recovery programme after oesophago-gastrectomy: a prospective cohort study. Int J Surg 2014; 12(4): 320-324.

10. Markar SR, Schmidt H, Kunz S, Bodnar A. Evolution of standardized clinical pathways: refining multidis-ciplinary care and process to improve outcomes of the surgical treatment of esophageal cancer. J Gastrointest Surg 2014; 18(7): 1238-1246.

11. Kobayashi S, Kanetaka K, Nagata Y, Nakayama M, Matsumoto $\mathrm{R}$, Takatsuki M, et al. Predictive factors for major postoperative complications related to gastric conduit reconstruction in thoracoscopic esophagectomy for esophageal cancer: a case control study. BMC Surg 2018; 18(1): 15-18.
12. Greco M, Capretti G, Beretta L, Gemma M. Enhanced recovery program in colorectal surgery: a meta-analy-sis of randomized controlled trials. World J Surg 2014; 38(6): 1531-1541.

13. Liu Q, Ding L, Jiang H, Zhang C, Jin J. Efficacy of fast track surgery in laparoscopic radical gastrectomy for gastric cancer: a meta-analysis of randomized controlled trials. Int J Surg 2018; 50(1): 28-34.

14. Kagedan DJ, Ahmed M, Devitt KS, Wei AC. Enhanced recovery after pancreatic surgery: a systematic review of the evidence. HPB (Oxford) 2015; 17(1): 11-16.

15. Qi S, Chen G, Cao P, Hu J, He G, Luo J, et al. Safety and efficacy of enhanced recovery after surgery (ERAS) programs in patients undergoing hepatectomy: A prospective randomized controlled trial. J Clin Lab Anal 2018; 32(6): e22434.

16. Tsujimoto H, Takahata R, Nomura S, Yaguchi Y, Kumano I, Matsumoto $Y$, et al. Video-assisted thoracoscopic surgery for esophageal cancer attenuates postoperative systemic responses and pulmonary complications. Surgery 2012; 151(5): 667-673.

17. Jiang K, Cheng L, Wang JJ, Li JS, Nie J. Fast track clinical pathway implications in esophagogastrectomy. World J Gastroenterol 2009; 15(4): 496-501.

18. Pan $\mathrm{H}, \mathrm{Hu} X, \mathrm{Yu} Z$, Zhang R, Zhang W, Ge J. Use of a fast-track surgery protocol on patients undergoing minimally invasive oesophagectomy: preliminary results. Interact Cardiovasc Thorac Surg 2014; 19(3): 441-447.

19. Lewis SJ, Andersen HK, Thomas S. Early enteral nutrition within $24 \mathrm{~h}$ of intestinal surgery versus later commencement of feeding: a systematic review and meta-analysis. J Gastrointest Surg 2009; 13(3): 569-575.

20. Liu YW, Yan FW, Tsai DL, Li HP, Lee YL. Expedite recovery from esophagectomy and reconstruction for esophageal squamous cell carcinoma after perioperative management protocol reinvention. J Thorac Dis 2017; 9(7): 2029-2037.

21. Gatenby PA, Shaw C, Hine C, Scholtes S, Koutra M, Andrew $\mathrm{H}$, et al. Retrospective cohort study of an enhanced recovery programme in oesophageal and gastric cancer surgery. Ann R Coll Surg Engl 2015; 97(7): 502-507.

22. Underwood TJ, Noble F, Madhusudan N, Sharland D, Fraser R, Owsley J, et al. The development, application and analysis of an enhanced recovery programme for major oesophagogastric resection. J Gastrointest Surg 2017; 21(4): 614-621.

23. Masabni K, Kandagatla P, Popoff AM, Rubinfeld I, Hammoud Z. Is esophagectomy for benign conditions benign?. Ann Thorac Surg 2018; 106(2): 368-374. 